to mammary duct carcinoma. Arch Klin Exp Ohren

Nasen Kehlkopfheilkd 1968;192:100-5.

2. Jayaprakash V, Merzianu M, Warren GW, et al. Survival rates and prognostic factors for infiltrating salivary duct carcinoma: Analysis of 228 cases from the Surveillance, Epidemiology, and End Results database. Head Neck 2014;36:694-701

3. Wee DT, Thomas AA, Bradley PJ. Salivary duct carcinoma: what is already known, and can we improve survival? J Laryngol Otol 2012;126 Suppl 2:S2-7.

4. Salovaara E, Hakala O, Back L, et al. Management and outcome of salivary duct carcinoma in major salivary glands. Eur Arch Otorhinolaryngol 2013;270:281-5.

5. Carr RJ, Bowerman JE. A review of tumours of the deep lobe of the parotid salivary gland. Br J Oral Maxillofac Surg 1986;24:155-68.

\section{Low-Grade Fibromyxoid Sarcoma of the Malar Area}

Jun Ho Lee ${ }^{1}$, Hwan Jun Choi ${ }^{1}$, Hae Yoen Jung ${ }^{2}$

Departments of ${ }^{1}$ Plastic and Reconstructive Surgery and ${ }^{2}$ Pathology, Soonchunhyang University College of Medicine, Cheonan, Korea

Correspondence: Hwan Jun Choi

Department of Plastic and Reconstructive Surgery, Soonchunhyang University College of Medicine, 31 Soonchunhyang 6gil, Dongnam-gu, Cheonan 31151, Korea

Tel: +82-41-570-2195, Fax: +82-41-574-6133,E-mail: medi619@hanmail.net

This work was supported by the Soonchunhyang University Research Fund.

No potential conflict of interest relevant to this article was reported.

Received: 8 Apr 2015 • Revised: 11 Jun 2015• Accepted: 19 Jun 2015 pISSN: 2234-6163 • elSSN: 2234-6171

http://dx.doi.org/10.5999/aps.2016.43.1.110

Arch Plast Surg 2016;43:110-112

Copyright (C) 2016 The Korean Society of Plastic and Reconstructive Surgeons This is an Open Access article distributed under the terms of the Creative Commons Attribution Non-Commercial License (http://creativecommons.org/licenses/by-nc/3.0/) which permits unrestricted non-commercial use, distribution, and reproduction in any medium, provided the original work is properly cited.

A 34-year-old female patient presented with a mass on the left malar area that had been palpable for 1 year. The mass had enlarged slowly. The patient complained of discomfort and had aesthetic concerns because of the increased size of the mass. She had no specific medical history. However, the patient had a history of trauma on the ipsilateral oral cavity at puberty. A physical examination revealed that there was a movable soft mass with a diameter of $2 \mathrm{~cm}$ and normal-appearing skin. There was no discoloration, erythema, and inflammation. On computed tomography (CT), a slightly diffuse enhancing lowdensity mass was seen on the subcutaneous layer adjacent to the zygomaticus muscle (Fig. 1). Removal of the mass was performed under general anesthesia by using an intraoral approach and a pull-through technique with a gingivobuccal incision. The mass was not easily separated from the surrounding tissues and zygomaticus muscles. The margin of the mass was intermingled with the surrounding fibrous tissue (Fig. 2). The lesion was completely excised with no remarkable occurrences (Fig. 3). Grossly, the mass was round, with a diameter of $1.3 \mathrm{~cm}$. The gross findings of the mass included a well-circumscribed, oval-to-round mass with a thin, fibrous pseudocapsule. The cut surface showed a whorled, whitegray, firm, and fibrous consistency with a homogenous appearance. A histological examination revealed a well-circumscribed mass with no capsulation (Fig. 4). The tumor primarily had a myxoid appearance and was hyper-cellular with bland spindle cells; it had minimal cytologic atypia, generally low mitotic activity and no necrosis, but there were abrupt transitions to collagen rosettes, which was a heavily collagenized area with sparse cellularity. The vasculature in the tumor showed an arcade appearance with hyalinization (Fig. 5). An immunohistochemical study showed that the tumor cells were focally positive for smooth muscle actin but negative for S-100, desmin, and CD34. The

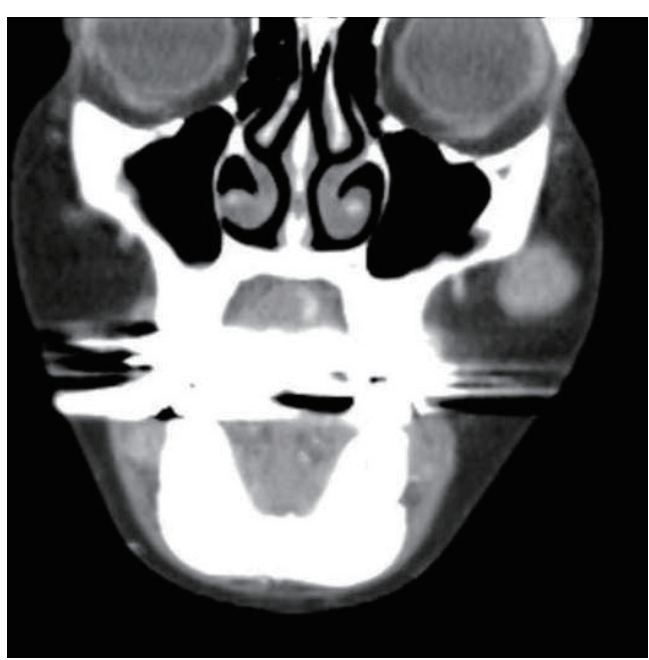

Fig. 1.

A computed tomography image of the mass: a slightly diffuse enhancing low-density mass on the left malar area on the coronal view. 
diagnosis of low-grade fibromyxoid sarcoma (LGFMS) was made on the basis of the collected results. There was no evidence of recurrence at the 8-month follow-up period.

Malignant soft-tissue tumors rarely occur in the head and neck, and surgeons are challenged in determining the optimal method for tumor excision, particularly in the case of tumors located in the face [1]. Moreover, an accurate diagnosis of soft-tissue tumors is often complicated even for well-trained pathologists because of the histologic characteristics of these tumors. LGFMS is a rare type of sarcoma, and the determination of the disease course based on oncologic and histologic features remains controversial [1]. LGFMS is a rare tumor type first described by Evans in 1987 [1]. In the original description, LGFMS was histologically characterized as a bland-appearing soft-tissue neoplasm, associated with aggressive behavior and a high degree of local recurrence or distant metastasis [2]. LGFMS is a rare

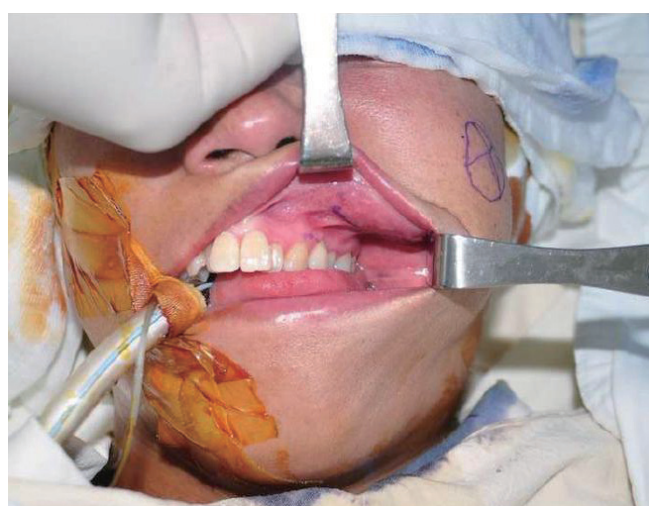

Fig. 2.

An intraoperative finding: the intraoral approach and the shape of the mass.

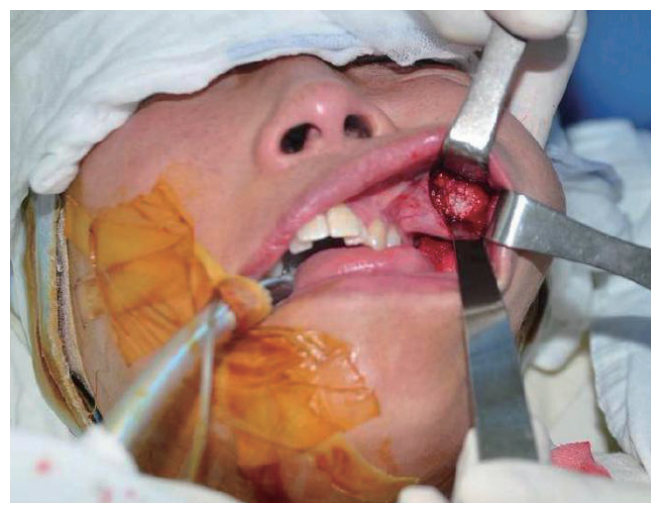

Fig. 3.

An intraoperative finding: the appearance of the exposed specimen. neoplasm that commonly occurs in young to middleaged adults. Males are more commonly affected than females [3]. The most frequently reported location of LGFMS is the lower extremity, particularly the thigh, followed by the trunk and groin, upper extremities, and buttocks $[1,2,4]$. The head and neck region is a very rare location for this type of sarcoma. LGFMS is frequently surrounded by skeletal muscle and typically presents as a painless deep soft-tissue mass [3]. CT and magnetic resonance imaging (MRI) are widely used, while ultrasonography (USG) is occasionally used for diagnosing the disease. Immunohistochemically, most cells of this sarcoma are strongly positive for vimentin but are generally negative for $\alpha$-smooth muscle actin, desmin, S-100 protein, cytokeratin, CD34, and CD56 [1]. The microscopic appearance of LGFMS exhibits bland fibroblastic spindle cells with a whorled or linear arrangement in the fibrous and myxoid areas [3]. The diagnosis of LGFMS is still difficult because of its characteristic bland-looking histologic features that can be confused with other benign or low-grade fibromyxoid lesions [3]. Although LGFMS shows a benign histologic appearance, local recurrence and late metastases have frequently been reported. Evans

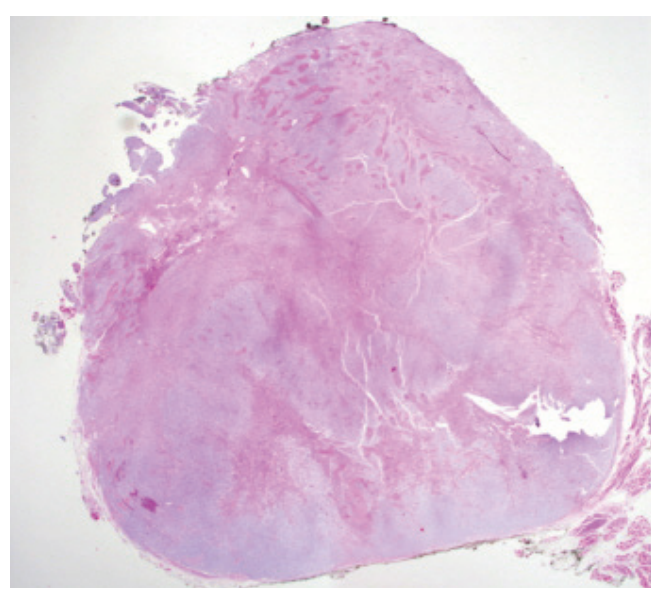

Fig. 4.

A microscopic examination: the tumor is wellcircumscribed and has a myxoid feature (bluish background) $\left(H \& E_{1} \times 20\right)$.

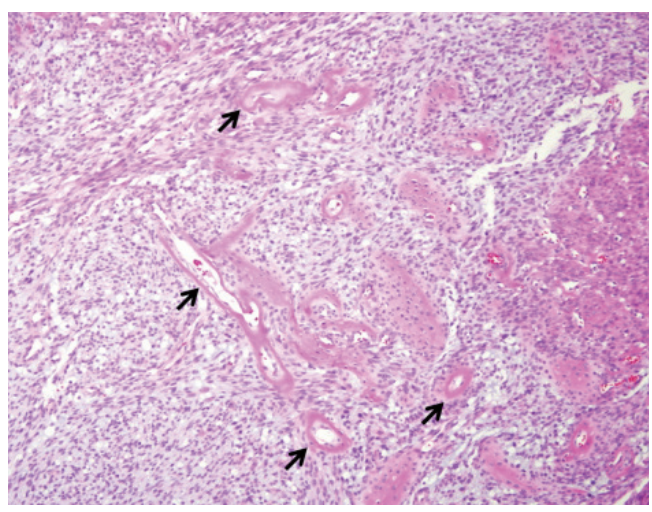

Fig. 5.

A microscopic examination: the tumor is hypercellular with spindle cells and contains small vessels with an arcade appearance (black arrows) $\left(H \& E_{1} \times 100\right)$. 
noted that some recurrent and metastatic tumors contain zones of increased cellularity and mitotic activity [2]. In this type of tumor, adequate surgical excision of the tumor is necessary because of the frequent recurrence of LGFMS [1]. The young patient age and superficial location likely contribute to a benign clinical diagnosis in many cases of superficial LGFMS. This clinical impression could potentially result in a delayed biopsy or excision and potentially worsen the patient outcome. The recommended treatment for LGFMS includes radical surgery, wide en bloc surgical resection, complete resection, compartmental excision, and local excision. Adjuvant radiotherapy or chemotherapy has not been recommended in previous reports. As these tumors are prone to metastasis after a long interval, sometimes after as many as 45 years, a thorough clinical follow-up is recommended. However, no study to date has recommended any protocol for the follow-up [5]. Thus, we described a rare case of facial LGFMS in a woman. She had no evidence of local recurrence or metastases at the postoperative 8-month follow-up.

\section{References}

1. Abe Y, Hashimoto I, Nakanishi H. Recurring facial lowgrade fibromyxoid sarcoma in an elderly patient: a case report. J Med Invest 2012;59:266-9.

2. Evans HL. Low-grade fibromyxoid sarcoma: a report of 12 cases. Am J Surg Pathol 1993;17:595-600.

3. Liao KS, Huang WT, Yang SF, et al. Intramuscular lowgrade fibromyxoid sarcoma: a case report. Kaohsiung J Med Sci 2009;25:448-54.

4. Folpe AL, Lane KL, Paull G, et al. Low-grade fibromyxoid sarcoma and hyalinizing spindle cell tumor with giant rosettes: a clinicopathologic study of 73 cases supporting their identity and assessing the impact of high-grade areas. Am J Surg Pathol 2000;24:1353-60.

5. Indap S, Dasgupta M, Chakrabarti N, et al. Low grade fibromyxoid sarcoma (Evans tumour) of the arm. Indian J Plast Surg 2014;47:259-62.

\section{Squamous Cell Carcinoma Arising from an Epidermal Inclusion Cyst}

Jin-Won Lee, Jin-Yong Shin, Si-Gyun Roh, Nae-Ho Lee, Kyung-Moo Yang

Department of Plastic and Reconstructive Surgery, Chonbuk National University Medical School, Jeonju, Korea

\section{Correspondence: Si-Gyun Roh}

Department of Plastic and Reconstructive Surgery, Chonbuk National

University Medical School, 20 Geonji-ro Deokjin-gu, Jeonju 54907, Korea Tel: +82-63-250-1860, Fax: +82-63-250-1866, E-mail: pssroh@jbnu.ac.kr

No potential conflict of interest relevant to this article was reported.

Received: 27 Mar 2015• Revised: 31 Jul 2015• Accepted: 31 Jul 2015 pISSN: 2234-6163 • elSSN: 2234-6171

http://dx.doi.org/10.5999/aps.2016.43.1.112 Arch Plast Surg 2016;43:112-114

Copyright (C) 2016 The Korean Society of Plastic and Reconstructive Surgeons This is an Open Access article distributed under the terms of the Creative Common Attribution Non-Commercial License (http://creativecommons.org/licenses/by-nc/3.0/ which permits unrestricted non-commercial use, distribution, and reproduction in any medium, provided the original work is properly cited.

Epidermal inclusion cysts are commonly encountered benign cystic lesions that can occur anywhere in the body. However, malignant changes are rare, and only a few cases of malignant change have previously been reported $[1,2]$.

Anton-Badiola et al. [2], based on a total of 13 reported cases, found that the mean age at presentation of squamous cell carcinoma arising from an epidermal inclusion cyst was 43.2 years. They also observed that it occurred more frequently in men, that the head and neck area was the most commonly

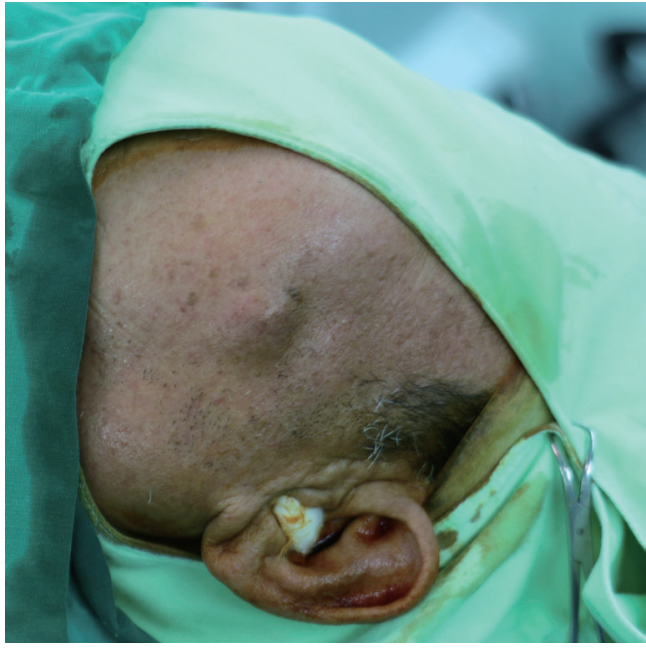

Fig. 1.

A 62-year-old male who presented with a $2 \times 2-\mathrm{cm}$ soft bulging mass on the left cheek. 